\title{
Early stages of core segregation recorded by Fe isotopes in an asteroidal mantle
}

\author{
Barrat Jean-Alix ${ }^{1,{ }^{*}}$, Rouxel Olivier ${ }^{2}$, Wang K. ${ }^{3}$, Moynier F. ${ }^{4,5}$, Yamaguchi A. ${ }^{6,7}$, Bischoff A. ${ }^{8}$, \\ Langlade Jessica $^{9}$
}

1 Univ Bretagne Occidentale, CNRS, UMR 6538, Inst Univ Europeen Mer, F-29280 Plouzane, France.

2 IFREMER, Ctr Brest, F-29280 Plouzane, France.

${ }^{3}$ Harvard Univ, Dept Earth \& Planetary Sci, Cambridge, MA 02138 USA.

${ }^{4}$ Univ Paris Diderot, Inst Univ France, Inst Phys Globe Paris, Sorbonne Paris Cite, F-75238 Paris 05,

France.

5 Inst Univ France, Paris, France.

${ }^{6}$ Natl Inst Polar Res, Tachikawa, Tokyo 1908518, Japan.

7 Grad Univ Adv Sci, Sch Multidisciplinary Sci, Dept Polar Sci, Tachikawa, Tokyo 1908518, Japan.

8 Univ Munster, Inst Planetol, D-48149 Munster, Germany.

${ }^{9}$ CNRS, UMS 3113, IUEM, F-29280 Plouzane, France.

*Corresponding author : Jean-Alix Barrat, email address : barrat@univ-brest.fr

\begin{abstract}
:
Ureilite meteorites are achondrites that are debris of the mantle of a now disrupted differentiated asteroid rich in carbon. They provide a unique opportunity to study the differentiation processes of such a body. We analyzed the iron isotopic compositions of 30 samples from the Ureilite Parent Body (UPB) including 29 unbrecciated ureilites and one ureilitic trachyandesite (ALM-A) which is at present the sole large crustal sample of the UPB. The $\delta 56 \mathrm{Fe}$ of the whole rocks fall within a restricted range, from 0.01 to $0.11 \%$, with an average of $+0.056 \pm 0.008 \%+0.056 \pm 0.008 \%$, which is significantly higher than that of chondrites. We show that this difference can be ascribed to the segregation of S-rich metallic melts at low degrees of melting at a temperature close to the Fe-FeS eutectic, and certainly before the onset of the melting of the silicates (View the MathML source $<1100^{\circ} \mathrm{C}$ ), in agreement with the marked $S$ depletions, and the siderophile element abundances of the ureilites. These results point to an efficient segregation of S-rich metallic melts during the differentiation of small terrestrial bodies.
\end{abstract}

\section{Highlights}

- Ureilites displays $\delta^{56} \mathrm{Fe}$ values higher than average chondrite. Segregation of Fe-sulfide melts explains the high $\delta^{56} \mathrm{Fe}$ values in ureilites. Formation of a core can begin at very low degrees of melting through the circulation of a Fe-S melt through a silicate mantle. 
Keywords : iron isotopes, achondrite, ureilite, core 
One of the most significant issues for understanding the differentiation of telluric bodies is

52 when and how their cores formed. Trace element abundances and $\mathrm{W}$ isotopic compositions obtained

53 on a series of iron meteorites indicate that the cores in the first differentiated planetesimals aggregated

54 metallic melts with various $\mathrm{S}$ contents, and formed from ca. 0.6 to 3 Myrs after the first solids

55 condensed in the Solar System (e.g., Blichert-Toft et al., 2010; Kruijer et al., 2014 and references

56 therein). The mechanisms of core formation are still highly debated, especially for the early stages of

57 the process. The percolation of $\mathrm{Fe}-\mathrm{S}$ melts into an olivine matrix has been suggested and

58 experimentally investigated, but the contribution of such melts to the cores of the planetary embryos or

59 of larger bodies, is a matter of debate (Bruhn et al., 2000; Yoshino et al., 2003; Bagdassarov et al.,

60 2009; Rushmer and Petford, 2011; Watson and Roberts, 2011). However, important constraints on the 
early stages of the differentiation of some small bodies are potentially recorded in their mantles, which can be investigated using meteorite samples.

Ureilites are remnants of the mantle of a now-disrupted carbon-rich body (Downes et al., 2008), and are among the most common achondrites in the meteorite collections (about 400 ureilites are currently reported in the Meteoritical Bulletin Database). They are ultramafic achondrites (e.g., Mittlefehldt et al., 1998) which are widely considered as mantle restites (Scott et al., 1993) formed after extraction of magmas and S-rich metallic melts. The vast majority of them are unbrecciated. They are coarse-grained peridotites consisting chiefly of olivine and pyroxenes (pigeonite, and more rarely augite and orthopyroxene), abundant carbon ( $<7 \mathrm{wt} \%$, graphite and diamond), with accessory metal and sulfides. Olivine grains classically have distinctive iron-depleted rims and veins (Fig. 1). They were formed by local reduction reactions with adjacent carbon. These rims give important constraints on the Ureilite Parent Body's (UPB) history. The Fe-Mg zonings of the olivines indicate that ureilites equilibrated at high temperatures $\left(1200-1300^{\circ} \mathrm{C}\right)$, and subsequently rapidly cooled down ( $\left.\sim 2-6^{\circ} \mathrm{C} / \mathrm{h}\right)$, consistent with impact-excavation or disruption of the UPB (e.g., Myiamoto et al., 1985). Except these rims and veins in olivine, silicates (i.e., olivine cores and pyroxenes) are quite uniform in $\mathrm{Mg} \#$ number $[=100 \mathrm{Mg} /(\mathrm{Mg}+\mathrm{Fe})$, atomic $]$ within any given ureilite. However, their compositions among samples show a huge variation, as shown by the olivine-core $\mathrm{Mg \#} \mathrm{(=} \mathrm{forsterite} \mathrm{content),} \mathrm{which}$ range from 74 to 97 . The $\mathrm{Fe} / \mathrm{Mn}$ ratios (ranging from 3 to 57 ) and $\Delta{ }^{17} \mathrm{O}$ values (= -0.2 to $-2.5 \%$ ) are correlated with this parameter (e.g., Clayton and Mayeda, 1996; Mittlefehldt et al., 1998; Fig. 2). The origin of these variations is a matter of discussions, but no consensus emerges at present. Certainly, they cannot be explained by igneous fractionation (e.g., Mittlefehldt et al., 1998). Instead, it has been often argued that the Mg\# range was ascribed to redox processes during the differentiation of the UPB or alternatively is inherited from the pre-igneous (nebular) history of the accreted materials (see Warren (2012) and Goodrich et al. (2013a) for extensive discussions of the current models on its origin).

A score of ureilites are polymict breccias consisting of debris of these peridotites, various chondritic clasts, and some feldspathic clasts which are remnants of the UPB's lavas (e.g., Cohen et 
al., 2004; Downes et al., 2008). A large clast (ALM-A) has been recently discovered among the numerous stones of the Almahata Sitta fall, and demonstrate that at least part of these melts was trachyandesitic (Bischoff et al., 2014).

Unlike asteroids such as Vesta whose $\mathrm{O}$ isotopic compositions were homogenized by a magma ocean (Greenwood et al., 2005), the wide range of $\Delta^{17} \mathrm{O}$ values displayed by the ureilites demonstrates that the UPB was never totally melted (Clayton and Mayeda, 1996). Nevertheless, it was heated enough to generate magmas (e.g. Cohen et al., 2004; Bischoff et al., 2014) and a small S-rich core (Warren et al., 2006; Rankenburg et al., 2008; Goodrich et al., 2013b).

Iron isotope ratios can track the involvement of iron sulfides during the early stages of the formation of the asteroidal cores. Marked enrichments in the lighter iron isotope are found in iron sulfides formed at ca. $1000^{\circ} \mathrm{C}$ or below (Schuessler et al., 2007; Polyakov and Soultanov, 2011; Wang et al., 2014), whereas no iron isotope fractionation has been detected between iron sulfide, metal and silicate melts at ca. $1250^{\circ} \mathrm{C}$ (e.g., Hin et al., 2012). Here, we report high-precision iron isotope compositions of 30 meteorites from the UPB, and show that its mantle displays iron isotopic compositions heavier than average chondrite. This indicates that a significant fraction of the sulfides was efficiently segregated during the early stages of the melting, possibly before the melting of the silicates. Therefore, core formation in an asteroid can begin at very low degrees of partial melting through the circulation of a Fe-S melt through a silicate mantle.

\section{Samples and analytical procedures}

We analyzed 30 meteorites from the UPB (29 unbrecciated ureilites and a unique lava sample, Table 1). Samples were kindly provided by the NASA meteorite working group (MWG), the National Institute of Polar Research (NIPR), the Ecole Normale Supérieure de Lyon (ENSL), the Westfälische Wilhelms-Universität Münster, the Washington University in Saint Louis, and finally from the first author's collection. The samples from Antarctica have been extensively studied by different teams. 
114 known (the references are too numerous to be cited here). Our meteorites from Sahara have been less

115 studied, and for most of them, only their descriptions in the Meteoritical Bulletin are available. They

116 are all regular ureilites. We have examined polished sections of all these samples to confirm their main

117 petrographical features, and determine the compositions of their silicates. The Saharan samples were

118 selected in order to complement the range of compositions displayed by the Antarctic ones. Although

119 the terrestrial weathering is pervasive in hot desert samples, the samples we selected were not severely

120 weathered, and display partly preserved metal and sulfides.

The major-element compositions of the phases were determined by electron microprobe analysis using a Cameca SX100 at Service Commun de Microsonde Ouest (SCMO), Plouzané, or a JEOL JXA8200 at NIPR (Table 2). Minerals and metal standards were used for calibration. All analyses used wavelength dispersive spectrometers at $15 \mathrm{kV}$ accelerating voltage, $10-30 \mathrm{nA}$ beam current at NIPR, and $20 \mathrm{kV}$ accelerating voltage, $40 \mathrm{nA}$ beam current with the same counting time as Pierre Hudon and David Mittlefehdt (in Downes et al., 2008) at Plouzané .

Fragments (each of 300-1,000 mg) were crushed to a homogeneous fine powder using a boron carbide mortar and pestle. Twenty mg of crushed material was digested by sequential mixtures of $\mathrm{HF} / \mathrm{HNO}_{3}, \mathrm{HNO}_{3}$ and $\mathrm{HCl}$ for the samples analyzed in Brest and in $\mathrm{HF} / \mathrm{HNO}_{3}$ and $\mathrm{HCl}$ for the samples analyzed in St Louis. These procedures allow a perfect dissolution of all the phases except graphite and diamond, which are Fe-free, have no effect for our study.

Aliquots of the solutions were used for the determination of the Fe and $\mathrm{Mg}$ concentrations of in the solutions were determined by ICP-AES (inductively coupled plasma-atomic emission spectrometry) using a Horiba Jobin Yvon Ultima 2 spectrometer in Plouzané, and the Mg\# numbers are given in Table 1. Iron in the dissolved samples was then purified by ion-exchange chromatography procedure previously described (Wang et al., 2012). The purification was repeated twice, thus ensuring the removal of all the matrix elements. A majority of the Fe isotopic compositions were measured on the Thermo Electron Neptune multi collector-inductively coupled plasma-mass

139 spectrometer housed at Ifremer, Plouzané, while the rest was analyzed in Saint Louis. In both Saint 140 Louis and Brest the instrument was operated in high resolution mode to resolve isobaric interferences, 
141 such as $\mathrm{ArO}$ on ${ }^{56} \mathrm{Fe}$, $\mathrm{ArOH}$ on ${ }^{57} \mathrm{Fe}$, and $\mathrm{ArN}$ on ${ }^{54} \mathrm{Fe}$. We also used the sample-standard bracketing

142 technique to correct for instrumental mass discrimination by normalizing Fe-isotope ratios to the

143 average measured composition of the standard that was run before and after the sample. In Plouzané,

144 we performed an additional correction using $\mathrm{Ni}$ as an internal standard for mass bias correction

145 (Dauphas and Rouxel, 2006). Fe isotope values are reported relative to the standard IRMM-14 using

146 the $\delta$-notation:

$$
\delta^{\mathrm{x}} \mathrm{Fe}=1000\left[\left({ }^{\mathrm{x}} \mathrm{Fe} /{ }^{54} \mathrm{Fe}\right)_{\text {sample }} /\left({ }^{\mathrm{x}} \mathrm{Fe} /{ }^{54} \mathrm{Fe}\right)_{\mathrm{IRMM}-14}-1\right] \text { where } \mathrm{x}=56 \text { or } 57 .
$$

Results for several georeference materials are similar to previously reported analyses (Table 3).

Errors are reported as 2 standard errors, which are calculated as the standard deviation divided by the square root of the total number of analyses and multiplied by the Student's t-value for the relevant degree of freedom at the 95\% confidence level. Results for the samples are listed in Table 4.

\section{Results}

The $\delta^{56} \mathrm{Fe}$ values obtained for 30 meteorites from the UPB, fall within a restricted range, from 0.01 to $0.11 \%$ (Fig. 3, Table 4). The mean of all these samples is significantly heavier $\left(\delta^{56} \mathrm{Fe}=0.056\right.$ $\pm 0.008 \%, \mathrm{n}=30$ ) than that of primitive meteorites, such as carbonaceous, ordinary and enstatite chondrites $\left(\delta^{56} \mathrm{Fe}=0.005 \pm 0.008 \%, \mathrm{n}=42\right.$, Craddock et al., 2013). The heavy $\mathrm{Fe}$ isotope composition displayed by the ureilites is striking because the early Solar Nebula was well homogenized for $\mathrm{Fe}$ isotopes (Schoenberg and von Blanckenburg, 2006; Wang et al., 2013), and because the Fe isotope compositions of the bulk silicate portions of most differentiated bodies investigated so far are chondritic [e.g., the Earth (Craddock et al., 2013), Mars and Vesta (Poitrasson et al., 2004; Weyer et al., 2005; Schoenberg and von Blanckenburg, 2006; Wang et al., 2012), and probably the Moon (Weyer et al., 2005; Halliday et al., 2013)]. One noteworthy exception is the angrite parent body whose lavas display high $\delta^{56} \mathrm{Fe}$ ratios $(\approx 0.12 \%$, Wang et al., 2012). 


\section{Discussion}

\subsection{Iron inventory in ureilites}

Iron in ureilites is hosted by many phases: silicates (olivine and pyroxenes), metal, sulfides, phosphides, carbide (cohenite), and their weathering products (Fig. 1). It is very difficult to obtain a reliable picture of the iron budget in ureilites from modal analyses. Goodrich et al. (2014) estimated that ureilites contain $\sim 1-3$ vol.\% of grain boundary metal, and less sulfides, in agreement with the abundances of metal and sulfur determined by chemistry (Vdovykin, 1970; Wänke et al., 1972; Hintenberger et al., 1978; Yanai et al., 1995). We used the standard wet chemical analyses compiled by Yanai et al. (1995) to estimate the proportions of Fe hosted by silicates, metal and troilite in ureilites (Fig. 4). Our calculations indicate that silicates are the main hosts of $\mathrm{Fe}$, and represent more than $70 \%$ of the budget of this element. Metal $(14-29 \%$ of the Fe budget) and sulfides $(<8 \%$ of the Fe budget) are clearly subordinate hosts. These conclusions are strengthened by the striking correlation between the $\mathrm{Mg} \#$ numbers $(=100 \times \mathrm{Mg} /(\mathrm{Mg}+\mathrm{Fe})$, atomic) of our samples and the composition of their olivine cores, which are representative of the Mg\# numbers of their silicates (Fig. $5)$.

\subsection{Origin of the high $\delta^{56} \mathrm{Fe}$ values in ureilites}

The high $\delta^{56} \mathrm{Fe}$ values in ureilites cannot be the result of terrestrial weathering. Alteration of sulfides in meteorites is accompanied by the release of light Fe. Heavier Fe isotopic compositions have been measured in weathered ordinary chondrite finds compared to fresh falls. However, the increase is rather limited, about $+0.07 \%$ of the $\delta^{56} \mathrm{Fe}$ were observed only for the most weathered $\mathrm{L}$ and $\mathrm{H}$ chondrites (Saunier et al., 2010). Ureilites are less prone to such an effect because sulfides control here a much lesser proportion of $\mathrm{Fe}$ than in $\mathrm{L}$ and $\mathrm{H}$ chondrites (Fig. 4). Although the alteration of ureilite finds is pervasive, our samples were not extensively weathered, and still displayed metal and sulfides. Indeed, the fresh fall samples (Novo Urey and Almahata Sitta) display the same isotopic compositions as find samples (Tables 1 and 4). 
Because the Fe isotopic compositions are certainly pristine, they could be inherited from the materials which accreted to form the UPB, or alternatively they could result of the differentiation of the UPB. A heavy Fe isotopic composition could be observed in bodies that suffered evaporative loss of volatile elements following high-energy impacts during accretion. This explanation was initially proposed for the Earth and the Moon by Poitrasson et al. (2004) but is controversial for these bodies (e.g., Halliday, 2013). It is probably valid for the angrite parent body (APB), where a strong depletion in volatile elements such as the alkalis, is accompanied by heavy $\mathrm{Fe}$ and $\mathrm{Si}$ isotopic compositions (Wang et al., 2012; Pringle et al., 2014). The UPB did not accrete from volatile depleted materials, because the magmas generated by the melting of its mantle were alkali and volatile-rich as shown by the compositions of the plagioclases in the feldspathic clasts found in polymict ureilites and the geochemistry of ALM-A, a trachyandesitic lava from the UPB (e.g., Cohen et al., 2004; Bischoff et al., 2014). Nevertheless, losses of volatile elements were possible during the disruption of the UPB, as shown previously for $\mathrm{Zn}$ (Moynier et al., 2010). However, the lack of correlation between $\delta^{56} \mathrm{Fe}$ values and abundances of volatile elements (e.g., $\mathrm{Zn}, \mathrm{Rb}, \mathrm{Li}$, not shown) rules out this possibility for Fe.

The high $\delta^{56} \mathrm{Fe}$ values in ureilites cannot be created by either the extraction of silicate melts, or by possible high temperature redox processes. Partial melting does not generate residues with $\delta^{56} \mathrm{Fe}$ values significantly distinct than those of the initial mantle (Weyer et al., 2005; Craddock et al., 2013).

High $\delta^{56} \mathrm{Fe}$ values in bulk rocks are certainly not the result of the reduction reactions that produced the Fe-depleted rims of the olivine during the disruption of the body. Although, the possibility of local isotopic heterogeneities in olivine have not yet been investigated, the possibility of a detectable effect is unlikely: 1/ the relative volume of the Fe-depleted rims is always limited (Fig. 1), and consequently the impact of these rims on the Fe budget is probably negligeable; $2 /$ the formation of the Fe-depleted olivine rims was a very fast process (e.g., Myiamoto et al., 1985), and a noticeable metal loss during the post-disruption cooling of the ureilites is not plausible; 3/ ALM-A, the ureilitic trachyandesite, displays a high $\delta^{56} \mathrm{Fe}$ value which indicates that this feature predates the disruption of the body. Moreover, the high $\delta^{56} \mathrm{Fe}$ values displayed by the ureilites are certainly not generated by the processes 
217 that produced the striking range of olivine-core compositions. The lack of correlation between the Fe 218 isotope compositions of ureilites and their olivine-core compositions demonstrates that both features 219 are unrelated (Fig. 2).

Alternatively, removal of S-rich metallic melts could explain the high $\delta^{56} \mathrm{Fe}$ values in ureilites. When a chondritic assemblage is heated, melting begins with Fe-sulfide (troilite) and metal at a temperature close to $980^{\circ} \mathrm{C}$ defined by the eutectic in the Fe-FeS system (Keil, 2000). Since at this temperature FeS displays a marked enrichment in the lighter Fe isotope (Schuessler et al., 2007, Polyakov and Soultanov, 2011; Wang et al., 2014), an increase of the $\delta^{56} \mathrm{Fe}$ value of the solid residue is anticipated. If the metallic melt is efficiently removed from the solid residue (fractional melting), all melting happens at the eutectic until either metal or troilite is exhausted. The effect on the isotopic compositions of the residues can be easily estimated.

The eutectic in the Fe-FeS system contains about 31.6 wt\% S and 68.4 wt\% Fe (e.g., Kullerud, 1963), and is equivalent to about $85 \mathrm{wt} \%$ troilite $+15 \mathrm{wt} \%$ metal. We calculate the $\Delta^{56} \mathrm{Fe}_{\text {metallic melt-silicate }}$

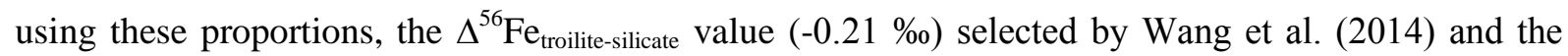
$\Delta^{56} \mathrm{Fe}_{\text {metal-troilite }}$ at ca. $1250 \mathrm{~K}(+0.1-+0.2 \%)$ estimated from theoretical calculations (Polyakov et al., 2007; Polyakov and Soultanov, 2011). For the calculations presented in Figure 6, we used a $\Delta^{56} \mathrm{Fe}_{\text {metallic melt-silicate }}=-0.18 \%$, and assumed that $\Delta^{56} \mathrm{Fe}_{\text {metallic melt-silicate }} \approx \Delta^{56} \mathrm{Fe}_{\text {metallic melt-residue. }}$

The composition of a source after extraction of a S-rich metallic melt at the eutectic were calculated using an isotope mass balance:

$$
\delta^{56} \mathrm{Fe}_{\text {source }}=\delta^{56} \mathrm{Fe}_{\text {metallic melt }} . f \mathrm{Fe}_{\text {metallic melt }}+\delta^{56} \mathrm{Fe}_{\text {residue }} \cdot f \mathrm{Fe}_{\text {residue }}
$$

where $f$ is the mass fraction of ${ }^{54} \mathrm{Fe}$ in the metallic melt or in the solid residue. This equation can be recast in terms of the residue:

$$
\delta^{56} \mathrm{Fe}_{\text {source }}=\left(\Delta^{56} \mathrm{Fe}_{\text {metallic melt-residue }}+\delta^{56} \mathrm{Fe}_{\text {residue }}\right)\left(1-f \mathrm{Fe}_{\text {residue }}\right)+\delta^{56} \mathrm{Fe}_{\text {residue }} \cdot f \mathrm{Fe}_{\text {residue }}(2)
$$

And consequently: 


$$
\delta^{56} \mathrm{Fe}_{\text {residue }}=\delta^{56} \mathrm{Fe}_{\text {source }}-\Delta^{56} \mathrm{Fe}_{\text {metallic melt-residue }}+\Delta^{56} \mathrm{Fe}_{\text {metallic melt-residue }} \cdot f \mathrm{Fe}_{\text {residue }} \text { (3) }
$$
on the initial $\mathrm{Fe}$ and $\mathrm{S}$ contents of the starting assemblage (Fig. 6). If the starting assemblage is Fe-rich and displays moderate $\mathrm{S}$ contents (e.g., like a $\mathrm{H}$ chondrite), segregation of the metallic melt produces at best a marginal shift of the isotopic composition of the residue. In contrast, for S-rich chondritic assemblages, an increase of ca. $0.1 \%$ of the $\delta^{56} \mathrm{Fe}$ can be achieved by this process. increases with the temperature. The composition of the metallic melt is consequently variable, and the situation becomes much more complex (melting of the silicates, involvement of carbon...). More importantly, fractionation of $\mathrm{Fe}$ isotopes between S-rich metallic melts and silicates becomes much less detectable with increasing temperature, and is usually supposed negligible considering our present level of precision, above $1250^{\circ} \mathrm{C}$ as determined through experimental studies (Poitrasson et al., 2009; Hin et al., 2012). [Notice that this view has been recently challenged by Shahar et al. (2015) whose results indicate significant fractionations between metallic melts and melted silicates at $1600^{\circ} \mathrm{C}$. However, the magnitude and direction of these isotopic fractionations are not consistent with the available analyses on magmatic irons (bulk samples) and the results presented here. A discussion of these results and previous ones is beyond the scope of this paper. Additional works are necessary to confirm these experimental results and to evaluate the effects of $\mathrm{B}$ or $\mathrm{Sn}$ used in previous experiments.]

Siderophile element systematics (e.g. platinum group elements) demonstrate that ureilites experienced separation of S-rich metallic melts, with possibly entrainment of metal (Warren et al., 2006; Rankenburg et al., 2008; Goodrich et al., 2013b), but the process (batch or fractional) and temperatures of segregation are not well constrained by these data. The heavy Fe isotopic compositions and the low S contents of the ureilites are consistent with the separation of S-rich metallic melts (Fig. 6), and indicate that the removal of these melts was efficient probably at a temperature close to the eutectic, and certainly before the onset of the melting of the silicates $(<1100$ 

${ }^{\circ} \mathrm{C}$ ). Indeed, ALM-A, the sole ureilitic lava sample available at present (Bischoff et al., 2014), displays a high $\delta^{56} \mathrm{Fe}$ value (Fig. 3), similar to the highest values measured on ureilites. Although partial melting can generate melts with Fe isotopic compositions heavier than their sources as exemplified by terrestrial basalts (e.g., Teng et al., 2013), this effect is negligible for mantles with low $\mathrm{Fe}^{3+} / \mathrm{Fe}_{\text {total }}$ ratios (Dauphas et al., 2014), like ureilites (Goodrich et al., 2013c). Consequently, ALM-A strongly suggests that the UPB's mantle acquired its specific isotopic composition early, before it was heated enough to generate magmas.

\subsection{Comparison with mantles of other small bodies.}

The heavy $\mathrm{Fe}$ isotopic compositions displayed by ureilites contrast with those of the brachinites and the olivines from the Main Group Pallasites, the samples of the other asteroidal mantles for which data are available (Fig. 3). Brachinites were possibly derived from multiple parent bodies. They are mantle restites similar to ureilites, but are more ferroan than the latter (Keil, 2014). GRA 06128/29, a brachinitic melt shows a light $\mathrm{Fe}$ isotopic composition $\left(\delta^{56} \mathrm{Fe}=-0.08 \pm 0.06 \%\right.$, which was ascribed to the involvement of Fe-sulfides during magma genesis (Wang et al., 2014). Probably because of the high Fe content of their protoliths, the average composition of the brachinites does not deviate from the chondritic value $\left(\delta^{56} \mathrm{Fe}=0.01 \pm 0.02 \%\right.$, $\mathrm{n}=7$, Wang et al., 2014), although S-rich metallic melts and sulfides were certainly involved during their differentiation (Day et al., 2012). Main Group Pallasites (MGPs) are mixtures of mantle-derived olivines and core-derived metal from a single disrupted asteroid (Greenwood et al., 2006). The homogeneous O isotopic composition of these pallasites provides a strong evidence for an early extensive melting event on their parent body, possibly resulting in the formation of a global magma ocean (Greenwood et al., 2006). Fe isotopes in MGPs cannot record the early stages of core segregation, because the temperatures reached during the global melting event were too high $\left(\gg>1300^{\circ} \mathrm{C}\right)$ to fractionate these isotopes between silicates and metallic melts. Indeed, the average $\mathrm{Fe}$ isotopic composition of olivines $\left(\delta^{56} \mathrm{Fe}=0.009 \pm\right.$ $0.014 \%, \mathrm{n}=11$, Weyer et al., 2005) is indistinguishable from the chondritic average. 


\section{Conclusions}

The marked $\mathrm{S}$ depletions, the siderophile element abundances and the high $\delta^{56} \mathrm{Fe}$ values displayed by ureilites point to an efficient segregation of S-rich metallic melts in the body, more likely before the onset of silicate melting. Although the UPB has been disrupted, samples of its core have not yet been recovered. The lack of such samples is not surprising because the number of meteorites from the UPB is still limited. The fact that only one large clast of ureilitic lava is actually known demonstrates that our ureilite meteorites provide only a partial sampling of the whole parent body.

The percolation of S-rich metallic melts has been extensively investigated in a solid matrix rich in olivine, analogous to an asteroidal mantle. Metallic melts over a percolation threshold ranging from about 6 vol\% to 18 vol\% (Yoshino et al., 2003; Bagdassarov et al., 2009; Watson and Roberts, 2011) can potentially create a stable interconnected network in an olivine-rich solid matrix that could have allowed the early segregation of some core material. Yet the permeability of the core forming FeFeS melts within a silicate matrix is very low, and it was inferred that percolation of these melts cannot be a major process of core formation in planetesimals (Watson and Roberts, 2011). The geochemical data on ureilites seem at odds with previous experiments. Certainly other factors can contribute to the segregation of Fe-FeS melts and to fast core formation in planetesimals, such as shear deformation of the body (Bruhn et al., 2000; Rushmer and Petford, 2011).

\section{Acknowledgements:}

Many samples analyzed during the course of this study were kindly provided by the National Institute of Polar Research and the NASA meteorite working group. US Antarctic meteorite samples are recovered by the Antarctic search for Meteorites (ANSMET) program which has been funded by NSF and NASA, and characterized and curated in the department of Mineral Sciences of the Smithsonian Institution and Astromaterials Curation Office at NASA Johnson Space Center. We thank Bernard Marty for the editorial handling, Hilary Downes, Franck Poitrasson, and an anonymous reviewer for their fast and constructive comments, Albert Jambon, Mathieu Roskosz and Richard Greenwood for discussions, and Pascale Barrat for her help. We gratefully acknowledge the Programme National de Planétologie (CNRS-INSU) for financial support. 


\section{References}

Bagdassarov, N., Golabek, G.J., Solferino, G., Schmidt, M.W. (2009) Constraints on the Fe-S melt connectivity in mantle silicates from electrical impedance measurements. Phys. Earth Planet. Inter. 177, 139-146.

Bischoff, A. et al. (2014) Trachyandesitic magmatism in the early Solar System. Proc. Natl. Acad. Sci. USA 111, 35, 1268912692.

Blichert-Toft J., Moynier F., Lee C.T.A., Telouk P., Albarede F. (2010) The early formation of the IVA iron meteorite parent body. Earth Planet. Sci. Lett. 296, 469-480.

Bruhn, D., Groebner, N., Kohlstedt, D.L. (2000) An interconnected network of core-forming melts produced by shear deformation. Nature 403, 883-886.

Cohen, B.A., Goodrich, C.A., Keil, K. (2004) Feldspathic clast populations in polymict ureilites: Stalking the missing basalts from the ureilite parent body. Geochim. Cosmochim. Acta 68, 4249-4266.

Clayton R.N., Mayeda T.K. (1996) Oxygen isotope studies of achondrites. Geochim. Cosmochim. Acta 60, 1999-2017.

Craddock, P.R., Dauphas, N. (2011) Iron isotopic compositions of geological reference materials and chondrites. Geostand. Geoanal. Res. 35, 101-123.

Craddock, P.R., Warren, J.M., Dauphas, N. (2013) Abyssal peridotites reveal the near-chondritic Fe isotopic composition of the Earth. Earth Planet. Sci. Lett. 365, 63-76.

Dauphas N. et al. (2014) Magma redox and structural controls on iron isotope variations in the Earth's mantle and crust. Earth Planet. Sci. Lett. 398, 127-140.

Dauphas, N., Rouxel, O. (2006) Mass spectrometry and natural variations of iron isotopes. Mass Spectrometry Reviews 25, 515-550.

Day, J.M.D. et al. (2012) Origin of felsic achondrites Graves Nunataks 06128 and 06129, and ultramafic brachinites and brachinite-like achondrites by partial melting of volatile-rich primitive parent bodies. Geochim. Cosmochim. Acta 81, 94128.

Downes, H., Mittlefehldt, D.W., Kita, N.T., Valley, J.W. (2008) Evidence from polymict ureilite meteorites for a disrupted and re-accreted single ureilite parent asteroid gardened by several distinct impactors. Geochim Cosmochim Acta 72, 48254844 .

Goodrich, C. A., Wlotzka, F., Ross, D. K. and Bartoschewitz, R. (2006) NWA 1500: plagioclase-bearing monomict ureilite or ungrouped achondrite? Meteorit. Planet. Sci. 41, 925-952.

Goodrich C.A., Wilson L., van Orman J.A., Michel P. (2013a) Comment on "Parent body depth-pressure-temperature relationships and the style of the ureilite anatexis" by P. H. Warren (MAPS 47:209-227) Meteoritics \& Planetary Science 48 1096-1106.

Goodrich, C. A., Ash, R. D., Van Orman, J. A., Domanik, K., McDonough, W. F. (2013b) Metallic phases and siderophile elements in main group ureilites: implications for ureilite petrogenesis. Geochim. Cosmochim. Acta 112, 340-373.

Goodrich C.A., Sutton S.R., Wirick S., Jercinovic M.J. (2013c) Chromium valences in ureilite olivine and implications for ureilite petrogenesis. Geochim. Cosmochim. Acta 122, 280-305.

Goodrich C.A., Harlow G.E., Van Orman J.A., Sutton S.R., Jercinovic M.J., Mikouchi T. (2014) Petrology of chromite in ureilites: Deconvolution of primary oxidation states and secondary reduction processes. Geochim. Cosmochim. Acta 135, 126-169.

Greenwood, R.C., Franchi, I.A., Jambon, A., Buchanan, P. (2005) Widespread magma oceans on asteroidal bodies in the early solar system. Nature $\mathbf{4 3 5}, \mathbf{9 1 6 - 9 1 8 . ~}$

Greenwood, R.C., Franchi, I.A., Jambon, A., Barrat, J.A., Burbine, T.H. (2006) Oxygen isotope variation in stony-iron meteorites. Science 313, 1763-1765.

Halliday, A.N. (2013) Small differences in sameness. Nature 497, 43-45. 
Hin, R.C., Schmidt, M.W., Bourdon, B. (2012) Experimental evidence for the absence of iron isotope fractionation between metal and silicate liquids at $1 \mathrm{GPa}$ and $1250-1300^{\circ} \mathrm{C}$ and its cosmochemical consequences. Geochim. Cosmochim. Acta 93, 164-181.

Hintenberger H., Jochum K.P., Braun O., Christ P., Martin W. (1978) The antarctic meteorite Yamato 74123 - a new ureilite. Earth Planet. Sci. Lett. 40, 187-193.

Keil, K. (2000) Thermal alteration of asteroids: evidence from meteorites. Planet. Space Sci. 48, 887-903.

Keil, K. (2014) Brachinite meteorites: Partial melt residues from an FeO-rich asteroid. Chemie der Erde 74, 311-329.

Kruijer, T.S. et al. (2014) Protracted core formation and rapid accretion of protoplanets. Science 344, 1150-1154.

Kullerud G. (1963) The Fe-Ni-S system. Ann. Rep. Geophys. Lab. 67, 4055-4061.

Mittlefehldt, D.W., McCoy, T.J., Goodrich, C.A., Kracher, A., (1998) Non-chondritic meteorites from asteroidal bodies. In: Papike, J.J.(Ed.), Planetary Materials. Mineralogical Society of America, Washington, DC, p.195.

Moynier F, Beck P., Yin Q.Z., Ferroir T., Barrat J.A., Paniello R., Telouk P., Gillet P. (2010) Volatilization induced by impacts recorded in $\mathrm{Zn}$ isotope composition of ureilites. Chem. Geol. 276, 374-379.

Myiamoto M., Takeda H., Toyoda H. (1985) Cooling history of some Antarctic ureilites. J Geophys. Res. 90, supplement, D116-D122.

Poitrasson, F., Halliday, A.N., Lee, D.C., Levasseur, S., Teutsch, N. (2004) Iron isotope differences between Earth, Moon, Mars and Vesta as possible records of contrasted accretion mechanisms. Earth Planet. Sci. Lett. 223, 253-266.

Poitrasson, F., Roskosz, M. and Corgne, A. (2009) No iron isotope fractionation between molten alloys and silicate melt to 2000 degrees $\mathrm{C}$ and $7.7 \mathrm{GPa}$ : experimental evidence and implications for planetary differentiation and accretion. Earth Planet. Sci. Lett. 278, 376-385.

Polyakov, V. B., Clayton, R. N., Horita, J. and Mineev, S. D. Equilibrium iron isotope fractionation factors of minerals: reevaluation from the data of nuclear inelastic resonant X-ray scattering and Mössbauer spectroscopy. Geochim. Cosmochim. Acta 71, 3833-3846 (2007).

Polyakov, V. B. and Soultanov, D. M (2011) New data on equilibrium iron isotope fractionation among sulfides: constraints on mechanisms of sulfide formation in hydrothermal and igneous systems. Geochim. Cosmochim. Acta 75, 1957-1974.

Pringle E.A., Moynier F., Savage P.S., Badro J., Barrat J.A. (2014) Silicon isotopes in angrites and volatile loss in planetesimals. Proc. Natl. Acad. Sci. USA, doi: 10.1073/pnas.1418889111.

Rankenburg, K., Humayun, M., Brandon, A. D., Herrin, J. S. (2008) Highly siderophile elements in ureilites. Geochim. Cosmochim. Acta 72, 4642-4659.

Rushmer T., Petford N. (2011) Microsegregation rates of liquid Fe-Ni-S metal in natural silicate-metal systems: A combined experimental and numerical study. Geochim Geophys. Geosyst. 12, Q03014, doi: 10.1029/2010GC003413.

Saunier G., Poitrasson F., Moine B., Gregoire M., Seddiki A. (2010) Effect of hot desert weathering on the bulk-rock iron isotope composition of L6 and H5 ordinary chondrites. Meteorit. Planet. Sci. 45, 195-209.

Schoenberg, R., von Blanckenburg, F. (2006) Modes of planetary-scale Fe isotope fractionation. Earth Planet. Sci. Lett. 252 , 342-359.

Schuessler, J.A., Schoenberg, R., Behrens, H., von Blanckenburg, F. (2007) The experimental calibration of the iron isotope fractionation factor between pyrrhotite and peralkaline rhyolitic melt. Geochim. Cosmochim. Acta 71, 417-433.

Scott, E.R.D., Taylor, G.J., Keil, K. (1993) Origin of ureilite meteorites and implications for planetary accretion. Geophys. Res. Lett. 20, 415-418.

Shahar, A. et al. (2015) Sulfur-controlled iron isotope fractionation experiments of core formation in planetary bodies. Geochim. Cosmochim. Acta 150, 253-264.

Singletary, S. J. and Grove, T. L. (2003) Early petrologic processes on the ureilite parent body. Meteorit. Planet. Sci. 38, 95108.

Teng F.Z., Dauphas N., Huang S., Marty B. (2013) Iron isotopic systematics of oceanic basalts. Geochim. Cosmochim. Acta 107, $12-26$ 
447

Vdovykin G. P. (1970) Ureilites. Space Sci. Rev. 10, 483-510.

Wang, K. et al. (2012) Iron isotope fractionation in planetary crusts. Geochim. Cosmochim. Acta 89, 31-45.

Wang, K. et al. (2013) Homogeneous distribution of Fe isotopes in the early solar nebula. Meteorit. Planet. Sci. 48, $354-364$.

Wang, K. et al. (2014) Iron isotope fractionation during sulfide-rich felsic partial melting in early planetesimals. Earth Planet. Sci. Lett. 392, 124-132.

Wänke H., Baddenhausen H., Spettel B., Teschke F., Quijano-Rico M., Dreibus G., Palme H. (1972) The chemistry of , $572-$ 590Haverö ureilite. Meteoritics 7, 579-590.

Warren P.H. (2011) Stable isotopes and the noncarbonaceous derivation of ureilites, in common with nearly all differentiated planetary materials. Geochim. Cosmochim. Acta 75, 6912-6926.

Warren P. H. (2012) Parent body depth-pressure-temperature relationships and the style of the ureilite anatexis. Meteoritics \& Planetary Science 47, 209-227.

Warren, P. H. and Rubin, A. E. (2010) Pyroxene-selective impact smelting in ureilites. Geochim. Cosmochim. Acta 74, 51095133.

Warren, P.H., Ulff-Moller, F., Huber, H., Kallemeyn, G.W. (2006) Siderophile geochemistry of ureilite: a record of early stages of planetesimal core formation. Geochim. Cosmochim. Acta 70, 2104-2126.

Wasson, J.T., Kallemeyn, G.W. (1988) Compositions of chondrites. Phil. Trans. R. Soc. London A 325, 535-544.

Watson, H.C., Roberts, J.J. (2011) Connectivity of core forming melts: Experimental constraints from electrical conductivity and X-ray tomography. Phys. Earth Planet. Inter. 186, 172-182.

Weyer, S. et al. (2005) Iron isotope fractionation during planetary differentiation. Earth Planet. Sci. Lett. 240, 251-264.

Yanai K., Kojma H., Haramura H. (1995) Catalog of the Antarctic meteorites. National Institute of Polar Research, Tokyo, $230 \mathrm{p}$.

Yoshino, T., Walter, M.J., Katsura, T. (2003) Core formation in planetesimals triggered by permeable flow. Nature 422, 154157. 
484 Table 1. Details of meteorite samples studied. Olivine compositions are from this study except D 485 (Downes et al., 2008), SG (Singletary and Grove, 2004), G (Goodrich et al., 2006), and WR (Warren 486 and Rubin, 2010).

$\begin{array}{cccc}\text { Source } & \# \text { or split } & \text { Ol. core } & \text { bulk rock } \\ & \text { Fo } \% & \text { Mg\# }\end{array}$

\section{Fall}

Novo Urei Saint Louis $\quad 78.5^{\mathrm{SG}}$

\section{Hot desert finds}

\begin{tabular}{|c|c|c|c|c|}
\hline El Gouanem & ENS Lyon & & $80.7^{\mathrm{SG}}$ & \\
\hline NWA 2236 & NIPR & ,41 & 96.8 & 91.8 \\
\hline NWA 4471 & $\mathrm{JAB}$ & & 78.1 & 70.2 \\
\hline NWA 4509 & ENS Lyon & & 78.5 & \\
\hline NWA 4511 & ENS Lyon & & 77.8 & 77.2 \\
\hline NWA 4512 & ENS Lyon & & 78.3 & \\
\hline NWA 4513 & ENS Lyon & & 90.5 & \\
\hline NWA 4516 & ENS Lyon & & 81.3 & 76.9 \\
\hline NWA 5555 & $\mathrm{JAB}$ & & 90.8 & 87.3 \\
\hline NWA 5602 & $\mathrm{JAB}$ & & 79.0 & 76.5 \\
\hline NWA 5884 & $\mathrm{JAB}$ & & 78.6 & 75.0 \\
\hline NWA 6056 & $\mathrm{JAB}$ & & 84.8 & 81.4 \\
\hline NWA 7349 & $\mathrm{JAB}$ & & 76.5 & 75.4 \\
\hline NWA 7630 & $\mathrm{JAB}$ & & 79.1 & 73.4 \\
\hline NWA 7686 & $\mathrm{JAB}$ & & 91.0 & 84.3 \\
\hline NWA 7880 & $\mathrm{JAB}$ & & 78.6 & 77.7 \\
\hline NWA 8049 & $\mathrm{JAB}$ & & 84.3 & 81.3 \\
\hline \multicolumn{5}{|l|}{ Antarctic finds } \\
\hline A-881931 & NIPR & ,65 & 78.7 & 76.5 \\
\hline ALHA 77257 & NIPR & ,104 & $86.1^{\mathrm{D}}$ & 83.7 \\
\hline ALH 82130 & MWG &, 43 & $95.2^{\mathrm{D}}$ & 89.9 \\
\hline EET 83225 & MWG &, 37 & $88.3^{\mathrm{D}}$ & 85.5 \\
\hline LAP 03587 & MWG &, 10 & $74.7^{\mathrm{WR}}$ & 74.1 \\
\hline LAR 04315 & MWG &, 46 & $81.9^{\mathrm{WR}}$ & 79.1 \\
\hline MET 01085 & MWG &, 23 & no olivine & 84.9 \\
\hline Y-791538 & NIPR & , 126 & $91.3^{\mathrm{D}}$ & 87.1 \\
\hline Y-981810 & NIPR &, 88 & 78.3 & 74.4 \\
\hline
\end{tabular}

Other finds

$\begin{array}{lll}\text { Kenna } & \text { Saint Louis } & 78.0^{\mathrm{G}} \\ \text { Goalpara } & \text { Saint Louis } & 76.6^{\mathrm{D}}\end{array}$

Ureilitic trachyandesite (Almahata Sitta fall) 
488 Table 2. Olivine core compositions of the samples analyzed during the course of this study (oxides in $489 \mathrm{wt} \%, \mathrm{Fe} / \mathrm{Mn}$ atomic).

490

\begin{tabular}{lccccccccccc}
\hline & lab. & $\mathrm{n}$ & $\mathrm{SiO}_{2}$ & $\mathrm{Cr}_{2} \mathrm{O}_{3}$ & $\mathrm{FeO}$ & $\mathrm{MnO}$ & $\mathrm{MgO}$ & $\mathrm{CaO}$ & total & $\mathrm{Fo} \%$ & $\mathrm{Fe} / \mathrm{Mn}$ \\
& & & & & & & & & & & \\
A-881931 & NIPR & 13 & 38.07 & 0.49 & 19.72 & 0.40 & 40.78 & 0.29 & 99.75 & 78.7 & 48.1 \\
NWA2236 & NIPR & 28 & 42.38 & 0.38 & 3.21 & 0.45 & 53.91 & 0.28 & 100.64 & 96.8 & 7.0 \\
NWA 4471 & SCMO & 10 & 38.75 & 0.49 & 19.92 & 0.39 & 39.92 & 0.29 & 99.76 & 78.1 & 50.1 \\
NWA 4509 & SCMO & 10 & 39.06 & 0.75 & 19.73 & 0.41 & 40.49 & 0.37 & 100.80 & 78.5 & 48.0 \\
NWA 4511 & SCMO & 10 & 38.80 & 0.54 & 20.32 & 0.40 & 40.03 & 0.31 & 100.40 & 77.8 & 50.7 \\
NWA 4512 & SCMO & 10 & 39.47 & 0.71 & 19.75 & 0.40 & 39.95 & 0.37 & 100.67 & 78.3 & 48.2 \\
NWA 4513 & SCMO & 10 & 40.82 & 0.59 & 9.08 & 0.43 & 48.52 & 0.30 & 99.74 & 90.5 & 20.8 \\
NWA 4516 & SCMO & 10 & 39.19 & 0.67 & 17.38 & 0.41 & 42.28 & 0.32 & 100.26 & 81.3 & 41.5 \\
NWA5555 & SCMO & 10 & 41.07 & 0.62 & 8.89 & 0.45 & 49.36 & 0.31 & 100.72 & 90.8 & 19.5 \\
NWA 5602 & SCMO & 10 & 38.60 & 0.72 & 19.32 & 0.41 & 40.88 & 0.35 & 100.28 & 79.0 & 46.3 \\
NWA5884 & SCMO & 10 & 39.32 & 0.70 & 19.36 & 0.40 & 39.92 & 0.32 & 100.06 & 78.6 & 47.4 \\
NWA6056 & SCMO & 10 & 40.26 & 0.75 & 14.27 & 0.44 & 44.73 & 0.39 & 100.87 & 84.8 & 31.8 \\
NWA 7349 & SCMO & 10 & 38.54 & 0.39 & 21.55 & 0.41 & 39.29 & 0.23 & 100.41 & 76.5 & 51.3 \\
NWA 7630 & SCMO & 10 & 38.89 & 0.74 & 19.26 & 0.41 & 40.78 & 0.33 & 100.40 & 79.1 & 46.6 \\
NWA 7686 & SCMO & 10 & 40.88 & 0.64 & 8.65 & 0.45 & 49.16 & 0.34 & 100.15 & 91.0 & 19.1 \\
NWA 7880 & SCMO & 10 & 38.82 & 0.74 & 19.69 & 0.40 & 40.58 & 0.28 & 100.54 & 78.6 & 49.2 \\
NWA 8049 & SCMO & 10 & 39.85 & 0.71 & 14.66 & 0.42 & 44.11 & 0.37 & 100.11 & 84.3 & 34.5 \\
Y-981810 & NIPR & 18 & 38.64 & 0.55 & 20.05 & 0.39 & 40.54 & 0.35 & 100.51 & 78.3 & 50.2 \\
\hline
\end{tabular}


494 Table 3. Iron isotopic compositions of international standards obtained during the course of this study 495 in Saint Louis and in Plouzané, and compared with literature values. (N\# = number of runs of the same 496 solution).

\begin{tabular}{|c|c|c|c|c|c|}
\hline & $\mathrm{N \#}$ & $\delta^{56} \mathrm{Fe}$ & 95\% C.I. & $\delta^{57} \mathrm{Fe}$ & 95\% C.I. \\
\hline \multicolumn{6}{|l|}{ BIR1 } \\
\hline Plouzané, average $(\mathrm{n}=6)$ & & 0.073 & \pm 0.017 & 0.116 & $\pm \mathbf{0 . 0 1 3}$ \\
\hline Wang et al. (2012) & & 0.043 & \pm 0.016 & 0.058 & \pm 0.026 \\
\hline Craddock \& Dauphas (2011) & & 0.053 & \pm 0.015 & 0.087 & \pm 0.023 \\
\hline \multicolumn{6}{|l|}{ BHVO2 } \\
\hline Plouzané, average $(\mathrm{n}=14)$ & & 0.117 & \pm 0.011 & 0.181 & $\pm \mathbf{0 . 0 2 3}$ \\
\hline Wang et al. (2012) & & 0.102 & \pm 0.012 & 0.159 & \pm 0.018 \\
\hline Craddock \& Dauphas (2011) & & 0.114 & \pm 0.011 & 0.174 & \pm 0.016 \\
\hline \multicolumn{6}{|l|}{ Allende USNM3529 } \\
\hline Plouzané \#1 & 5 & 0.015 & \pm 0.015 & 0.014 & \pm 0.069 \\
\hline Plouzané \#2 & 5 & 0.021 & \pm 0.035 & -0.019 & \pm 0.039 \\
\hline Plouzané, average (n=2) & & 0.018 & & -0.003 & \\
\hline Craddock \& Dauphas (2011) & & -0.007 & \pm 0.012 & 0.003 & \pm 0.019 \\
\hline \multicolumn{6}{|l|}{ AC-E } \\
\hline Plouzané \#1 & 5 & 0.316 & \pm 0.025 & 0.501 & \pm 0.065 \\
\hline Wang et al. (2012) & & 0.313 & \pm 0.018 & 0.457 & \pm 0.028 \\
\hline Craddock \& Dauphas (2011) & & 0.320 & \pm 0.010 & 0.478 & \pm 0.015 \\
\hline
\end{tabular}


500 Table 4. Iron isotopic compositions of unbrecciated and trachyandesitic ureilites.

\begin{tabular}{|c|c|c|c|c|c|c|}
\hline & lab. & $\mathrm{N \#}$ & $\delta^{56} \mathrm{Fe}$ & 95\% C.I. & $\delta^{57} \mathrm{Fe}$ & 95\% C.I. \\
\hline \multicolumn{7}{|l|}{ Fall } \\
\hline Novo Urei \#1 & St Louis & 9 & 0.024 & \pm 0.030 & 0.027 & \pm 0.050 \\
\hline Novo Urei \#2 & St Louis & 9 & 0.039 & \pm 0.038 & 0.084 & \pm 0.057 \\
\hline \multicolumn{7}{|c|}{ Northwest Africa finds } \\
\hline El Gouanem & St Louis & 9 & 0.068 & \pm 0.028 & 0.085 & \pm 0.052 \\
\hline NWA 2236 & Plouzané & 6 & 0.076 & \pm 0.017 & 0.129 & \pm 0.047 \\
\hline NWA 4471 & Plouzané & 8 & 0.086 & \pm 0.021 & 0.133 & \pm 0.033 \\
\hline NWA 4509 & St Louis & 9 & 0.024 & \pm 0.033 & 0.060 & \pm 0.058 \\
\hline NWA 4511 \#1 & Plouzané & 8 & 0.051 & \pm 0.032 & 0.073 & \pm 0.052 \\
\hline NWA 4511 \#2 & St Louis & 8 & 0.023 & \pm 0.032 & 0.062 & \pm 0.059 \\
\hline NWA 4512 & St Louis & 8 & 0.046 & \pm 0.032 & 0.082 & \pm 0.059 \\
\hline NWA 4513 & St Louis & 9 & 0.054 & \pm 0.038 & 0.098 & \pm 0.057 \\
\hline NWA 4516 & Plouzané & 9 & 0.047 & \pm 0.030 & 0.073 & \pm 0.044 \\
\hline NWA 5555 & Plouzané & 7 & 0.053 & \pm 0.031 & 0.081 & \pm 0.047 \\
\hline NWA 5602 & Plouzané & 10 & 0.043 & \pm 0.029 & 0.065 & \pm 0.049 \\
\hline NWA 5884 & Plouzané & 7 & 0.057 & \pm 0.017 & 0.087 & \pm 0.028 \\
\hline NWA $6056 \# 1$ & Plouzané & 5 & 0.040 & \pm 0.025 & 0.027 & \pm 0.027 \\
\hline NWA $6056 \# 2$ & Plouzané & 7 & 0.054 & \pm 0.021 & 0.080 & \pm 0.035 \\
\hline NWA 7349 & Plouzané & 8 & 0.059 & \pm 0.018 & 0.094 & \pm 0.027 \\
\hline NWA 7630 & Plouzané & 7 & 0.081 & \pm 0.026 & 0.124 & \pm 0.037 \\
\hline NWA 7686 \#1 & Plouzané & 5 & 0.090 & \pm 0.017 & 0.117 & \pm 0.066 \\
\hline NWA 7686 \#2 & Plouzané & 7 & 0.067 & \pm 0.029 & 0.103 & \pm 0.047 \\
\hline NWA 7880 & Plouzané & 6 & 0.040 & \pm 0.022 & 0.063 & \pm 0.030 \\
\hline NWA 8049 & Plouzané & 7 & 0.067 & \pm 0.031 & 0.109 & \pm 0.055 \\
\hline \multicolumn{7}{|l|}{ Antarctic finds } \\
\hline A-881931 & Plouzané & 5 & 0.109 & \pm 0.039 & 0.209 & \pm 0.062 \\
\hline ALHA 77257 & Plouzané & 6 & 0.058 & \pm 0.030 & 0.079 & \pm 0.057 \\
\hline ALH 82130 & Plouzané & 8 & 0.044 & \pm 0.034 & 0.053 & \pm 0.045 \\
\hline EET 83225 & Plouzané & 6 & 0.035 & \pm 0.026 & 0.038 & \pm 0.067 \\
\hline LAP $03587 \# 1$ & Plouzané & 7 & 0.035 & \pm 0.030 & 0.075 & \pm 0.016 \\
\hline LAP $03587 \# 2$ & St Louis & 9 & 0.055 & \pm 0.033 & 0.082 & \pm 0.058 \\
\hline LAR 04315 & Plouzané & 6 & 0.059 & \pm 0.029 & 0.088 & \pm 0.057 \\
\hline MET 01085 & Plouzané & 6 & 0.023 & \pm 0.023 & 0.036 & \pm 0.055 \\
\hline Y-791538 & Plouzané & 6 & 0.071 & \pm 0.018 & 0.121 & \pm 0.045 \\
\hline Y-981810 & Plouzané & 5 & 0.077 & \pm 0.015 & 0.125 & \pm 0.073 \\
\hline \multicolumn{7}{|l|}{ Other finds } \\
\hline Kenna & St Louis & 9 & 0.009 & \pm 0.030 & 0.030 & \pm 0.049 \\
\hline Goalpara \#1 & St Louis & 9 & 0.048 & \pm 0.030 & 0.095 & \pm 0.049 \\
\hline Goalpara \#2 & St Louis & 9 & 0.056 & \pm 0.038 & 0.092 & \pm 0.057 \\
\hline \multicolumn{7}{|c|}{ Ureilitic trachyandesite } \\
\hline ALM-A \#1 & Plouzané & 5 & 0.095 & \pm 0.032 & 0.155 & \pm 0.066 \\
\hline ALM-A \#2 & Plouzané & 4 & 0.096 & \pm 0.019 & 0.107 & \pm 0.045 \\
\hline ALM-A \#3 & Plouzané & 8 & 0.105 & \pm 0.023 & 0.159 & \pm 0.038 \\
\hline
\end{tabular}



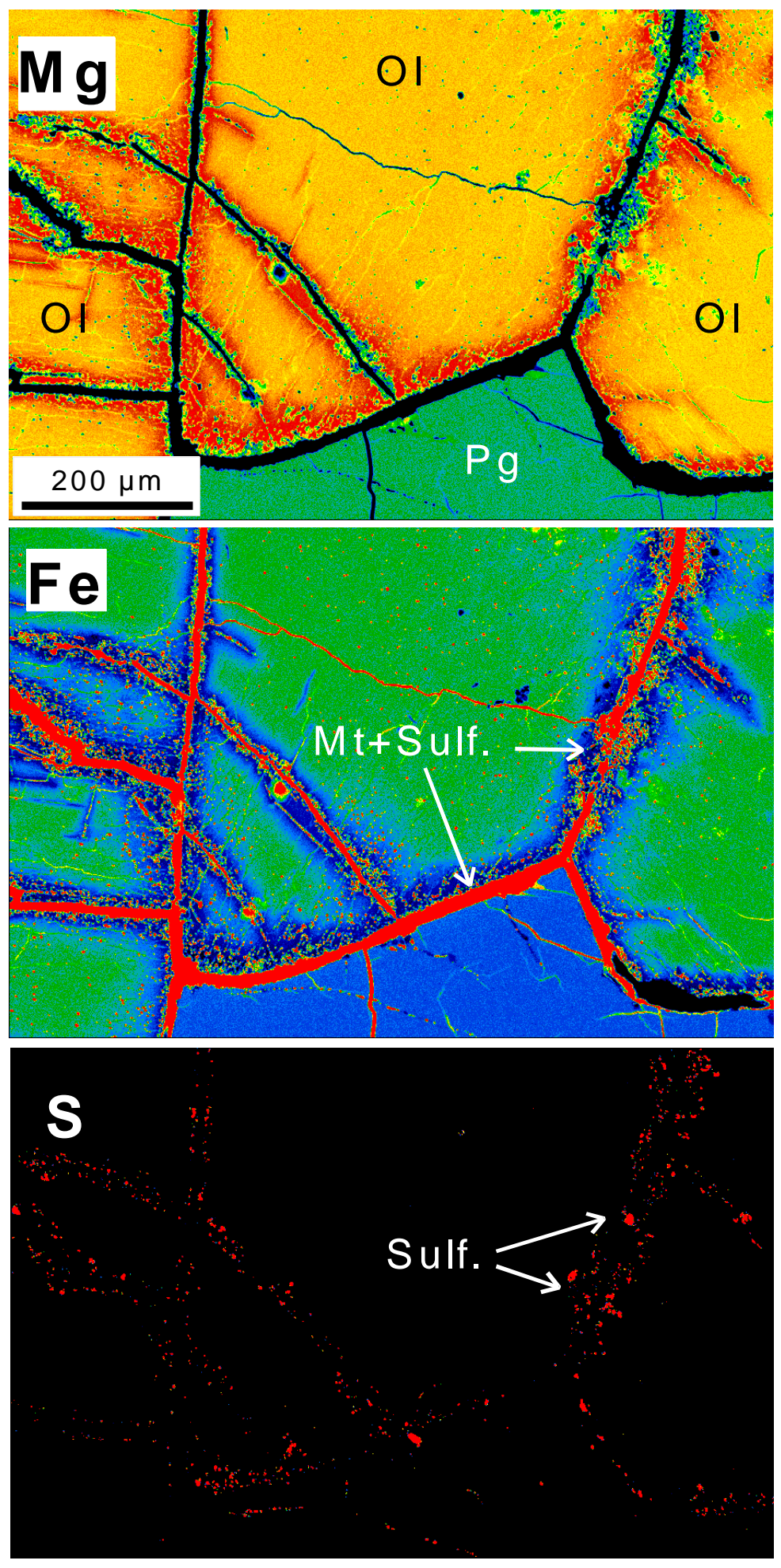

Figure 1. Maps of Mg, Fe and S of Northwest Africa 8049, a typical ureilite, showing the zoning of the olivine grains $(\mathrm{Ol})$, the homogeneity of the pigeonite $(\mathrm{Pg})$, and the repartition of metal $(\mathrm{Mt}$ - mainly interstitial and in tiny inclusions into olivine) and sulfides (Sulf.). 


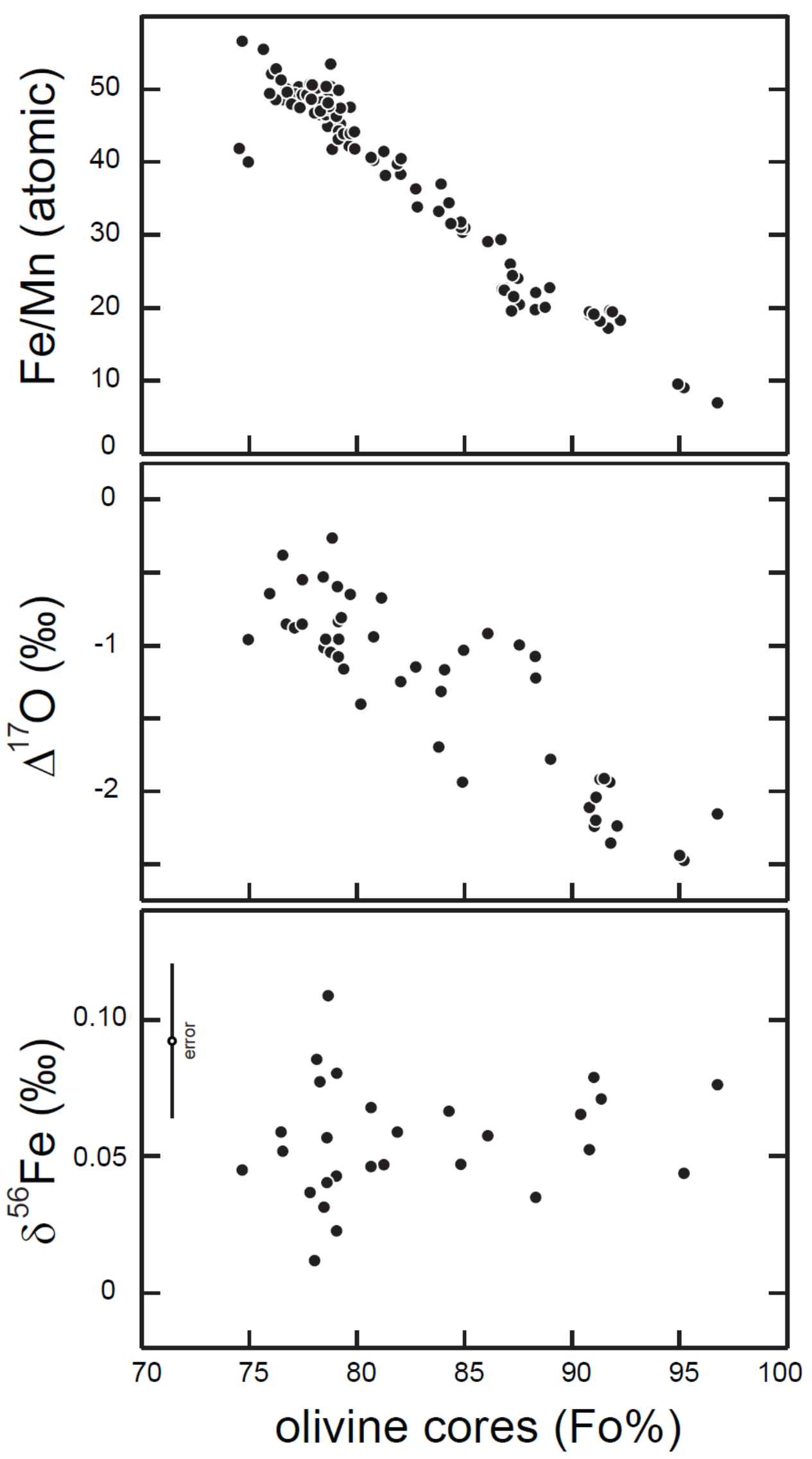

Figure 2. Plots of molar Fe/Mn ratios in olivine cores, $\Delta^{17} \mathrm{O}$ (Clayton and Mayeda, 1996) and $\delta^{56} \mathrm{Fe}$ in the bulk 514 rocks vs. the composition of the olivine cores (data from Table 2, and mainly from Downes et al. (2008), 515 Singletary and Grove (2003), Goodrich et al. (2006, 2014) and references therein). 

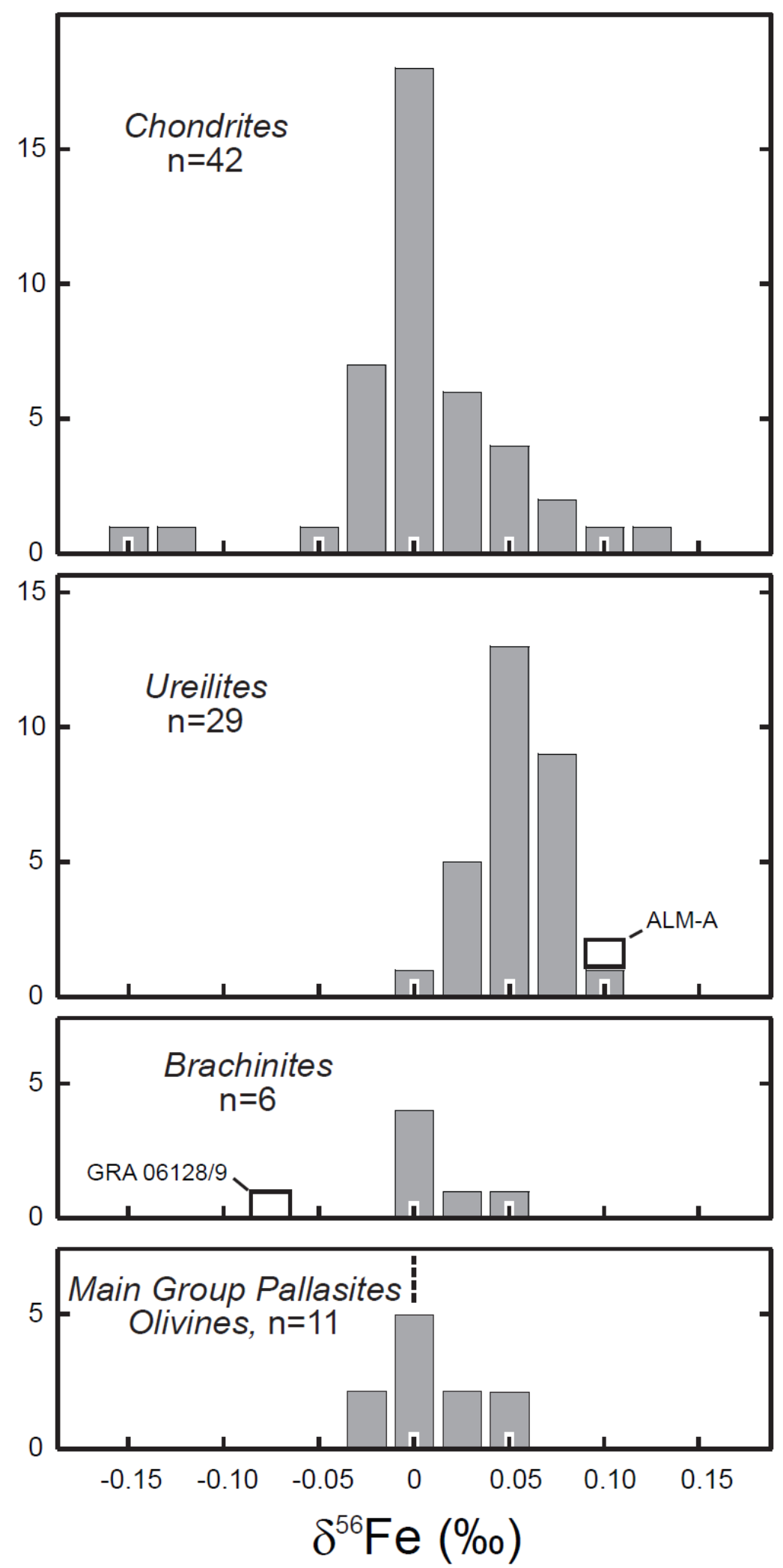

Figure 3. Iron isotope frequency distributions of chondrites (Craddock et al., 2013), ureilites and ALM-A, a ureilitic lava (this work), brachinites and GRA 06128/9, a brachinitic melt (Wang et al., 2014), and olivines from main group pallasites (Weyer et al., 2005). 


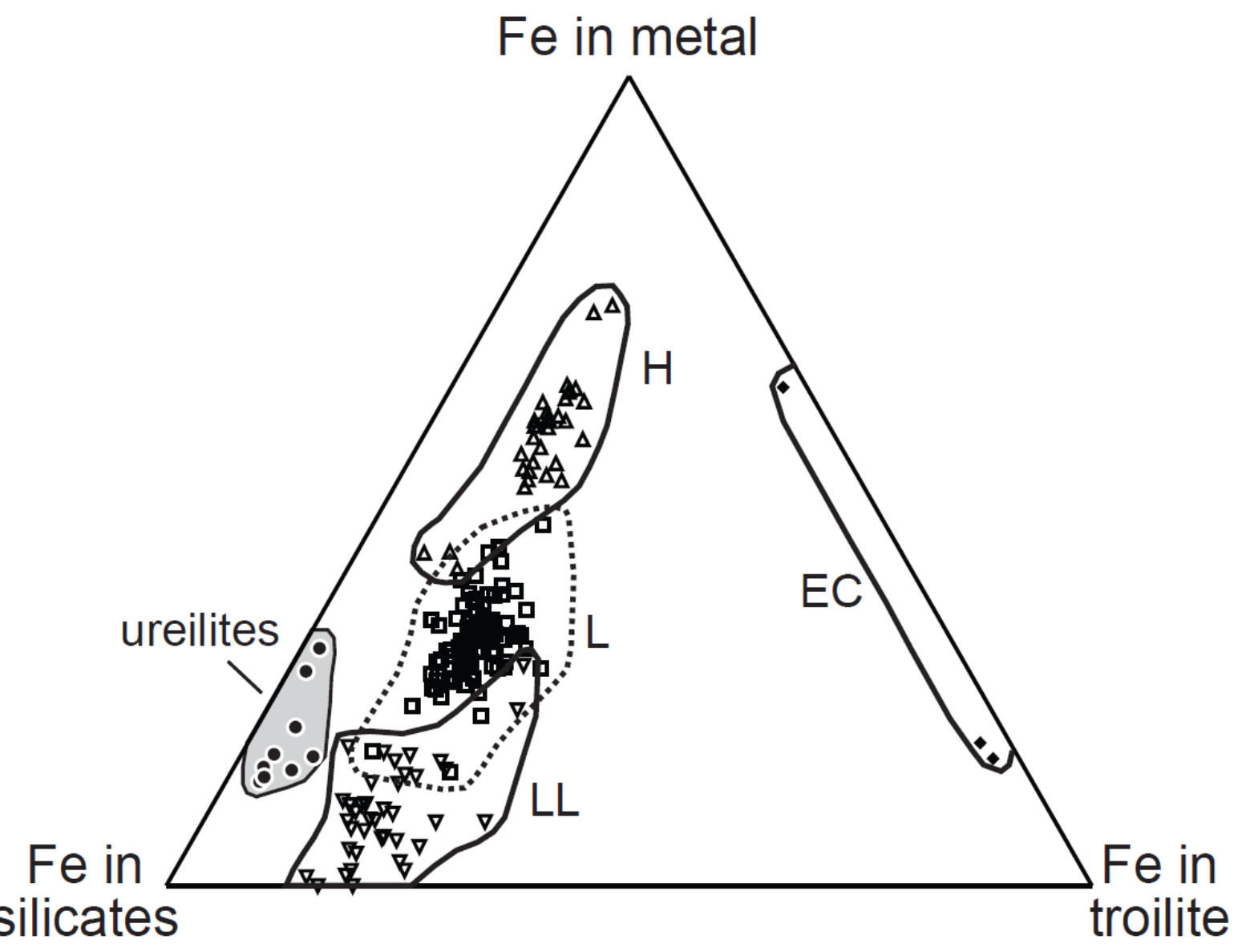

Figure 4. Ternary diagram showing the proportions of Fe hosted in the silicates, in metal and in sulfides for 


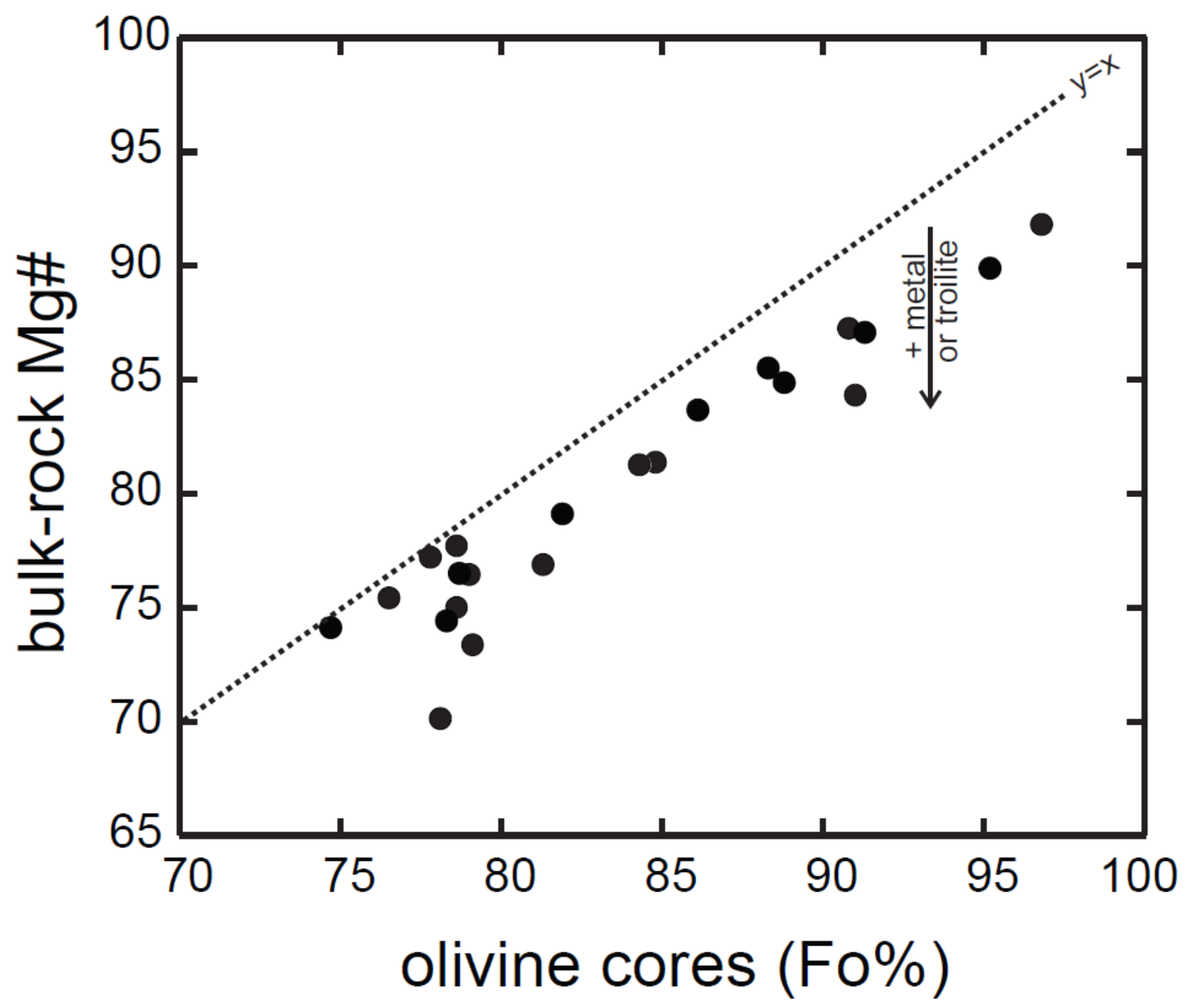

Figure 5. Bulk-rock Mg\# values vs. olivine-core compositions for the ureilites analyzed in Plouzané. 


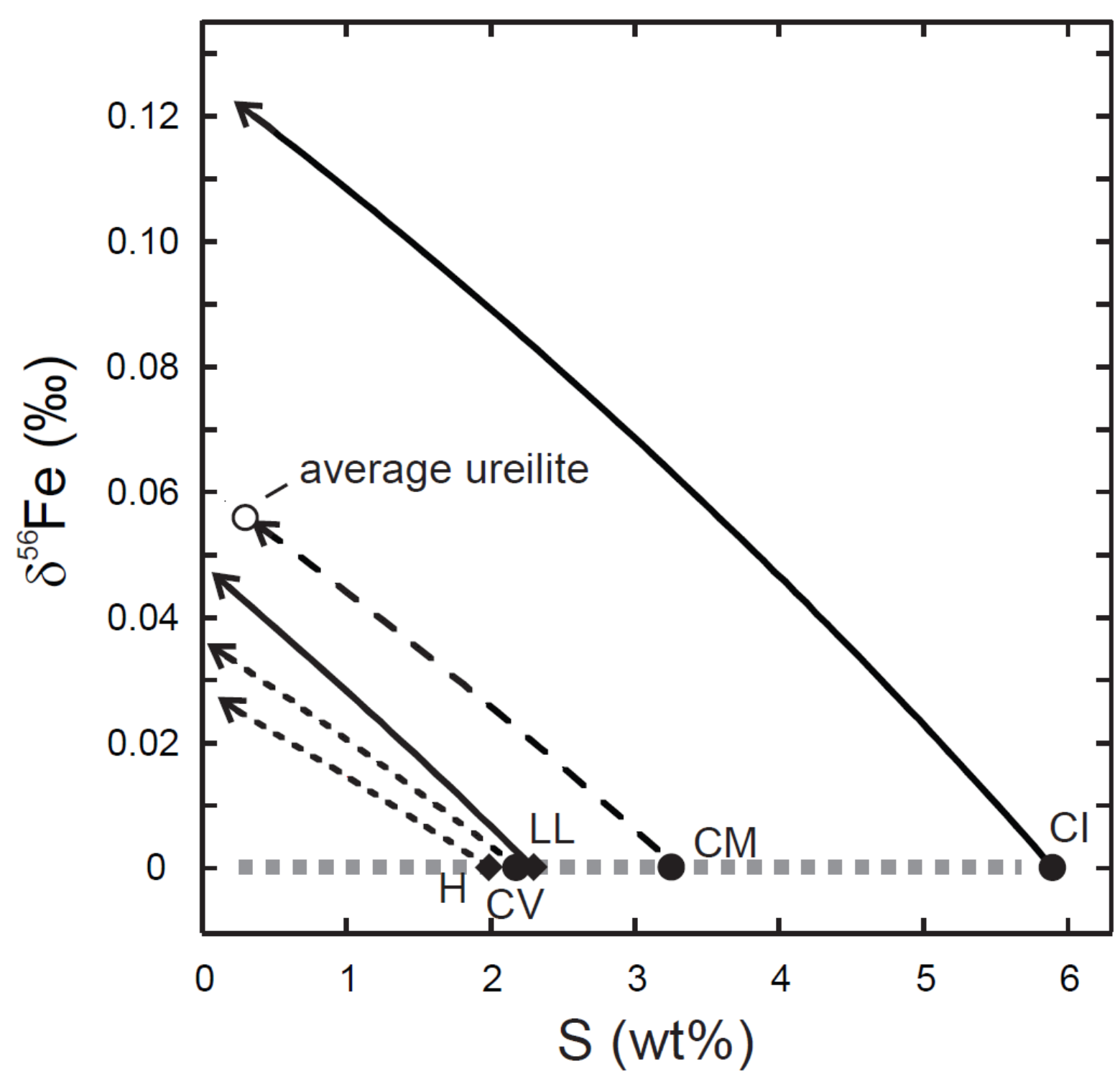

Figure 6. Evolution of the isotopic compositions of residual lithologies as a function of the extraction of a FeFeS melt with a eutectic composition. Starting assemblages have a $\delta^{56} \mathrm{Fe}=0 \%$ and the Fe and S contents of selected chondritic types (Wasson and Kallemeyn, 1988). The S abundance in the average ureilite is from Warren et al. (2006). A protolith with $\mathrm{S}$ and $\mathrm{Fe}$ abundances similar to average CM can account for the ureilite features, but this solution is not unique. Notice that the protolith of the ureilites is not a known carbonaceous chondrite (Warren, 2011). 